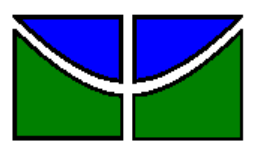

Universidade de Brasília

Faculdade de Economia, Administração e Contabilidade

Departamento de Administração

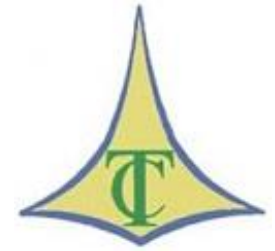

Tribunal de Contas do Distrito Federal

Dúcleo de Estudos e Pesquisas

\title{
ANÁLISE ECONÔMICA DOS GASTOS PÚBLICOS NOS MUNICÍPIOS BRASILEIROS: uma abordagem em dados em painel
}

Brasília - DF 


\section{RODRIGO NOLETO PAZ}

\section{ANÁLISE ECONÔMICA DOS GASTOS PÚBLICOS NOS MUNICÍPIOS BRASILEIROS: uma abordagem em dados em painel}

Trabalho de Conclusão de curso apresentado ao Departamento de Administração como requisito parcial à obtenção do título de especialista em Controle Externo.

Professor Orientador: Dr. André Luiz Marques Serrano

Brasília - DF 


\section{SUMÁRIO}

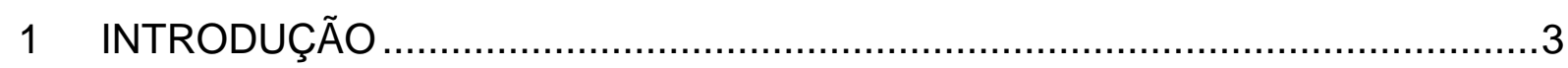

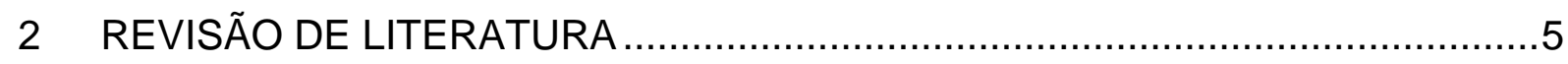

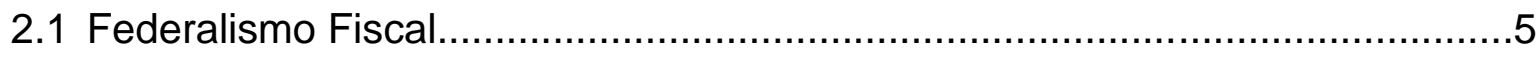

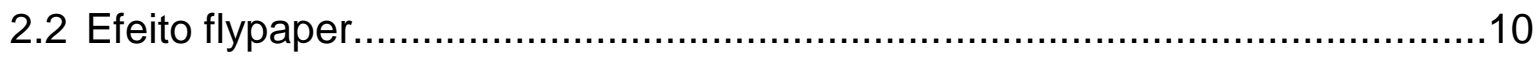

3 PROCEDIMENTOS METODOLÓGICOS..................................................15

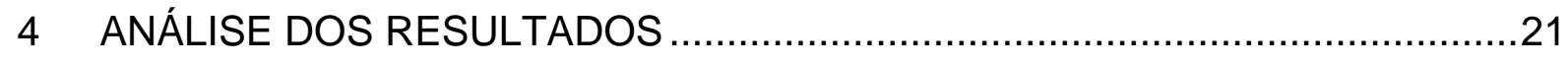

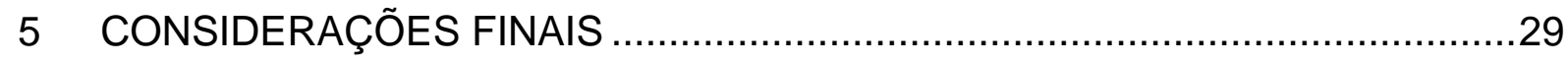

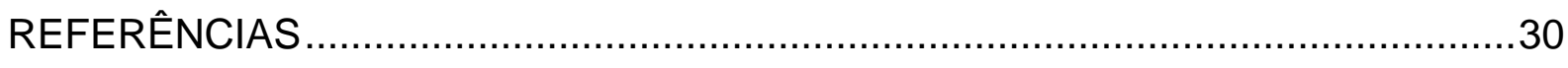




\section{INTRODUÇÃO}

Ao longo dos últimos exercícios, entes subnacionais vêm relegando para segundo plano questões que envolvem o planejamento das ações governamentais, o que traz desequilíbrios na alocação de recursos e, por conseguinte, na execução dos gastos públicos. Reflexo disso são as crises fiscais trivialmente observadas no âmbito dos estados e municípios brasileiros, em que o ritmo de execução da despesa se encontra, em muitos casos, superior ao da receita.

Nesse sentido, a teoria do federalismo fiscal surge como fator importante nesse processo de alocação de recursos entre os diversos entes da federação. Essa interação estimula a própria concorrência entre os entes, ao tempo em que tende a aumentar a eficiência na provisão de bens e serviços públicos, comparativamente à ofertada por uma administração rígida e centralizada.

As transferências intergovernamentais decorrentes do pacto federativo podem ensejar aumento nos gastos públicos dos entes autônomos que recebem tais recursos, principalmente aqueles decorrentes de arrecadação tributária. Estudos anteriores sobre o tema já indicaram que, ao menos em tese, o acréscimo das despesas públicas poderia acontecer em ritmo superior ao valor arrecadado oriundo de repasses. Tal fenômeno é conhecido na literatura como efeito flypaper.

No atual contexto das finanças municipais, as consequências do efeito flypaper podem ser nefastas às contas públicas, pois, além de contribuir para o desbalanceamento entre receitas e despesas, estimula o crescimento da dívida pública, trazendo impactos diretos na sustentabilidade a longo prazo.

O presente trabalho tem por objetivo geral verificar a ocorrência do efeito flypaper nos municípios brasileiros. Dada a natureza híbrida do Distrito Federal, tal ente também será considerado no presente estudo. Com sua realização, é possível atribuir ao efeito flypaper se o crescimento dos gastos públicos nos municípios brasileiros é imputável aos repasses intergovernamentais.

A título exemplificativo, pode-se ressaltar os trabalhos desenvolvidos por Correia (2014) e por Rios e Costa (2005), que fizeram verificações semelhantes às propostas nesta oportunidade. Vale lembrar que tais trabalhos tiveram por escopo 
regiões específicas, ao contrário da investigação abrangente que se pretende com esta pesquisa, com a proposta de analisar o aludido efeito para todos os municípios do país para os quais haja disponibilidade de dados.

Elucidada essa breve contextualização, tem-se o seguinte problema de pesquisa: "O comportamento dos gastos públicos no âmbito dos municípios brasileiros condiz com o efeito flypaper"?

São objetivos específicos deste trabalho caracterizar o efeito flypapere analisar se o comportamento dos gastos públicos nos municípios brasileiros retrata 0 fenômeno.

O trabalho está estruturado em cinco tópicos. Este tópico corresponde ao problema de pesquisa e ao objetivo a ser buscado com o trabalho. O próximo referese à revisão de tópicos específicos de finanças públicas com vistas à compreensão do efeito flypaper. Já o terceiro tópico traz breve abordagem da metodologia adotada e da descrição dos dados. Em seguida, tem-se os resultados apresentados e as discussões pertinentes. Por fim, a quinta seção trata das conclusões e sugestões para novas pesquisas na área. 


\section{REVISÃO DE LITERATURA}

Nas subseções seguintes, serão discutidos os conceitos de federalismo fiscal e do efeito flypaper, necessários para compreensão dos objetivos deste trabalho.

\subsection{Federalismo fiscal}

O federalismo é um sistema de governo em que o poder é dividido entre o governo central e os regionais, sendo meio termo entre governo unitário (concentrado em uma única entidade política) e confederação (cujo poder central é fraco ou mesmo nulo). Por meio do pacto federativo, entes políticos autônomos se organizam e relacionam entre si, de modo a formar um todo, uma única unidade também autônoma (COSER, 2008).

O federalismo se traduz na própria forma de exercício do poder estatal e na influência que os entes subnacionais podem exercer em cada um de seus territórios. Isso se reflete nas mais variadas formas de estabelecimento de poderes, como por exemplo as províncias, distritos, estados, munícipios e tantas outras observadas ao longo da história. No caso brasileiro, pode-se constatar a junção dos Estados, que resultou na unidade central denominada União.

Nesse relacionamento entre federações, a descentralização fiscal (também denominada de federalismo fiscal) passou a ganhar cada vez mais importância no estudo das finanças públicas. Trata-se de mera restrição do conceito tradicional de federalismo, em que se configura a esfera de governo responsável pela arrecadação de receitas, pela execução de despesas e pela forma de organização do sistema da transferência de recursos de um ente a outro (LIMA, 2015).

Em simetria à concepção original de federalismo, a descentralização fiscal assume a faceta da própria razão de ser do Estado, no tocante a duas importantes alçadas assumidas pelos entes políticos autônomos: 1) o poder de arrecadação de receitas, mediante exercício da autoridade coercitiva do Estado, afirmando sua superioridade perante o particular, ou até mesmo por intermédio de atividades empresariais com o intuito de obter renda, em que o Estado e particular se encontram 
em pé de igualdade; e 2) o poder de despender recursos, de maneira a prover bens e serviços públicos para a sociedade (MENDES, 2013).

Segundo Lima (2015), o federalismo fiscal insere-se no contexto de atribuição de responsabilidades com vistas à obtenção de receitas e ao controle de gastos públicos e das transferências de recursos, ou seja, qual ente é responsável por arrecadar, por despender e por repartir recursos aos demais governos locais.

Assim, o conceito de federalismo fiscal está intimamente relacionado à atividade financeira do Estado. Para Jund (2008), a atividade financeira do Estado trata-se de instrumental necessário à obtenção de recursos, com o objetivo de viabilizar o atendimento e a satisfação das necessidades públicas. Nesse sentido, percebe-se ampla responsabilidade dos entes federativos em "garantir e assegurar não só a manutenção da estrutura administrativa estatal, mas igualmente de satisfazer as necessidades públicas por meio do gasto do dinheiro público (PISCITELLI, 2011)".

Dentro desse escopo, tem-se a obtenção de receitas públicas, a criação de crédito público (endividamento), a gestão do orçamento governamental e o dispêndio de despesas públicas (JUND, 2008). Assim, a captação, a geração e o gasto de recursos objetivam prover os serviços estatais e atender as demandas coletivas (BALEEIRO, 1997).

A descentralização fiscal não deixa de retratar a forma de interação dos mercados de bens privados para regular a oferta e demanda de bens públicos. Os governos locais assumem o papel de provedores, com atuação bem próxima à verificada nas firmas inseridas no mercado de bens privados. Já as famílias (consumidores) estimulam a curva de demanda, em que optam por pagar o "preço" (na forma de tributos) para usufruir dos bens públicos de sua preferência (ARVATE; BIDERMAN, 2004).

Como maneira de compreender a conjuntura do tema, é relevante registrar alguns trabalhos que procuraram justificar a adoção do federalismo fiscal pelas nações. Por exemplo, tem-se a competição entre governos locais como aspecto positivo para implantação do federalismo fiscal nas nações, denominado de concorrência horizontal. A mobilidade da sociedade poderia fazer com que fossem reveladas suas preferências por bens públicos, de modo a facilitar sua provisão em nível ótimo. Assim, a medida incentivaria os governos a ofertarem cestas de bens 
públicos cada vez melhores à população, cabendo aos indivíduos decidirem os próprios locais de residência, tendo por ônus o financiamento da estrutura governamental escolhida mediante pagamento de tributos. Por outra via, traz como fator limitador a presença de externalidades e até mesmo a própria mobilidade entre localidades (TIEBOUT, 1956).

Em um segundo momento, Oates (1972) ressalta a importância tanto do governo central, quanto dos governos locais, no processo de maximização da eficiência do setor público. Sob essa concepção, o federalismo fiscal tenderia a compatibilizar as competências e características inerentes de cada um dos entes políticos, gerando uma sinergia de tal forma que a concorrência entre os diversos níveis de governo tornaria a interação vantajosa, por intermédio de ações cooperativas horizontais (entre governos locais) e verticais (entre governo central e subnacional). Pode-se citar, a título exemplificativo, a repartição de funções entre os demais níveis políticos e a maior participação e fiscalização nas decisões tomadas. Por também considerar os benefícios da interatividade com o governo central, as ponderações de Oates conflitam com aquelas apresentadas por Tiebout (1956), pois a concorrência horizontal não possui capacidade de elevar a eficiência econômica por si só.

Já Gordon (1983) trouxe à tona o impacto das externalidades em economias descentralizadas, até então consideradas como fator limitador nos estudos de Tiebout (1956). Para o autor, a intensidade dos efeitos externos (sejam eles positivos ou negativos) seria tanto maior quanto fosse o nível de descentralização observado no setor público. Isto é, a complexidade do sistema federativo oportuniza o aparecimento de falhas de mercado dessa natureza, o que poderia incitar a perda de eficiência econômica. Entre as externalidades, destacam-se a exportação de tributos a não residentes, os free-riders (caronas), a regressividade tributária e a guerra fiscal (ARVATE; BIDERMAN, 2004).

Apesar de existirem restrições quanto ao alcance dessa eficiência, compreender o alcance das externalidades não deixa de ser uma maneira eficaz para reduzi-las, permitindo normatizar um modelo de pacto federativo consistente. Dessa forma, o federalismo fiscal ainda é considerado importante técnica de atuação do Estado, que incentiva o aumento de autonomia dos governos nas decisões fiscais e, 
por conseguinte, no aumento da parcela destinada ao orçamento dos entes federados (GUEDES; GASPARINI, 2007).

O arcabouço legal e institucional vigente no Brasil contempla a repartição de competências e de receitas, também denotado de sistema de equalização tributária. Nesse contexto, tem-se o financiamento fiscal realizado pelos governos superiores (União e Estados) aos inferiores (Municípios) e os subsequentes efeitos dos repasses nos gastos públicos municipais. O comportamento dos gastos públicos em resposta às transferências intergovernamentais é melhor compreendido a partir da discussão aprofundada do flypaper effect, na seção seguinte. A Tabela 1 relaciona alguns estudos relacionados à temática. 
Tabela 1 - Estudos sobre o efeito flypaper.

\begin{tabular}{|c|c|c|}
\hline Autor & Objetivo & Resultado \\
\hline Araújo e Siqueira (2016) & $\begin{array}{l}\text { Estimar os efeitos da ilusão fiscal sobre a demanda } \\
\text { por gasto público municipal no Brasil. }\end{array}$ & $\begin{array}{l}\text { De acordo com o teorema do eleitor mediano, } \\
\text { estimou-se uma função demanda por bens e } \\
\text { serviços públicos locais que inclui variáveis que } \\
\text { captam ilusão fiscal. Os resultados evidenciaram } \\
\text { que ilusão fiscal associada à estrutura tributária e } \\
\text { às transferências fiscais contribui para a } \\
\text { compreensão da expansão gasto público no Brasil. }\end{array}$ \\
\hline Correia (2014) & $\begin{array}{l}\text { Analisar se o comportamento dos gastos públicos } \\
\text { nos municípios cearenses condiz com a prática } \\
\text { definida pela literatura como efeito flypaper. }\end{array}$ & $\begin{array}{l}\text { Verificou-se que o efeito flypaper não condiz com } \\
\text { a realidade das administrações municipais do } \\
\text { Ceará. }\end{array}$ \\
\hline Severo Filho (2012) & $\begin{array}{l}\text { Analisar a existência do efeito flypaper nos } \\
\text { municípios cearenses, para o ano de } 2000 \text {. }\end{array}$ & $\begin{array}{l}\text { Concluiu-se que alguns grupos não sofreram } \\
\text { influência do efeito flypaper. No entanto, na } \\
\text { maioria dos municípios cearenses, constatou-se } \\
\text { que o efeito existe, o que requer maior esforço } \\
\text { fiscal dos municípios e também expansão da } \\
\text { descentralização fiscal, visando mitigar o efeito } \\
\text { flypaper. }\end{array}$ \\
\hline
\end{tabular}

Fonte: Elaboração própria. 


\subsection{Efeito flypaper}

No campo de estudo das finanças públicas, existem correntes doutrinárias diversas que procuram explicar os motivos que levam as despesas públicas crescerem ao longo do tempo.

Adolf Wagner formulou a teoria que ficou conhecida como Lei do Crescimento Incessante das Atividades Estatais, ou "Lei de Wagner". Segundo a concepção, à medida que o nível de renda dos países industrializados cresce, os dispêndios sempre crescem a taxas mais elevadas, sendo a elasticidade-renda superior à unidade nesses casos (SILVA, 1979). Com efeito, o crescimento do setor público acompanha o desenvolvimento econômico, situação imputável à própria demanda por serviços públicos de qualidade (BURKHEAD, 1971).

Em sentido oposto à visão de Wagner, economistas atribuem o crescimento das despesas públicas à oferta de serviços públicos mediante tributação, e não à demanda. Os dispêndios tenderiam a crescer em situações de crise, momento que a sociedade não apresentaria maior resistência à criação ou aumento de tributos. Tal fenômeno é denominado de efeito translação, ou efeito do limite tributário (PEACOCK; WISEMAN, 1970).

Veja-se, contudo, que nenhuma dessas concepções confronta diretamente o comportamento dos gastos públicos com o efeito gerado por repasses intergovernamentais. Daí a importância do modelo flypaper em justificar a variação das despesas executadas pelos governos locais em decorrência da receita advinda do sistema de transferências (SAKURAI, 2013).

As primeiras evidências a respeito da ocorrência do efeito flypaper foram elucidadas por Courant, Gramlich e Rubinfeld (1979), no qual afirmam que está relacionado à preferência de os burocratas e políticos evitarem a redução de impostos quando o governo recebe fundos de repartição de receitas, do que a elevação de tributos quando algum evento exógeno resulta em aumento de renda da comunidade.

A origem do termo flypaper effect remete-se ao fato de que "money sticks where it hits", cuja tradução é "o dinheiro gruda onde encosta", em clara referência às moscas que pousam em papéis papa-moscas. Isto é, o recurso captado pela comunidade tem por origem o próprio setor público (governo responsável pela transferência), e este 
recurso fica ali mantido, não transitando ao setor privado (ARVATE; BIDERMAN, 2004).

Pode-se entender o efeito flypaper como o alto grau de sensibilidade (elasticidade) dos gastos públicos do ente federado, em virtude do montante arrecadado decorrente de transferências advindas de outros governos. A hipótese ilustraria a seguinte situação: quanto maior é a quantidade de recursos repassados por outros entes federativos, 0 gasto público do ente recebedor seria proporcionalmente maior à renda obtida (SEVERO FILHO, 2012).

Dessa forma, o efeito flypaper pode gerar distorções no sistema de repartição de receitas, bem assim o descompasso na execução orçamentária e financeira do ente federativo, de modo que as despesas superem as receitas, ampliando os gastos governamentais. Para manutenção do equilíbrio fiscal, entes tomam empréstimos e elevam a dívida pública, comprometendo sua sustentabilidade a longo prazo (SAKURAI, 2013).

Em outras palavras, sob um cenário em que a premissa do efeito flypaper seja verdadeira, há maior propensão para que os entes beneficiários aumentem suas despesas em resposta aos subsídios lump-sum, comparativamente aos aumentos percebidos pelo setor privado (RIOS; COSTA, 2005).

O fenômeno simboliza, portanto, a tendência de que transferências intergovernamentais recebidas por governos subnacionais ocasionem elevações nos gastos públicos, ao invés de serem redistribuídas ao setor privado mediante redução de impostos (WYCOFF, 1988).

Cientistas políticos e economistas defendem que o efeito flypaper faz com que ajudas intergovernamentais estimulem a execução das despesas públicas em ritmo superior aos comparáveis com rendimentos fundamentados sob o modelo de certeza de ilusão fiscal, no entanto, quando posta em prática, a descentralização fiscal vem geralmente acompanhada de descontrole nos gastos dos governos locais, o que pressiona as finanças públicas dos governos locais e centrais, prejudicando a política econômica do país (TURNBULL, 1998).

Há de se destacar que, em regra, a demanda por gastos públicos reflete a abordagem do teorema do eleitor mediano. O princípio aduz que a massa de políticos deseja majorar as chances de serem eleitos. Para alcançar esse objetivo, as escolhas 
que envolvem a provisão de bens e serviços públicos à sociedade satisfazem as necessidades do eleitor médio, o que significa que, dentro de um sistema de eleição majoritário, devem ser contentadas as preferências do eleitorado relevante, aqui entendido como aquele responsável por determinar a base de governantes institucionalizada. Assim, as ações voltadas à satisfação das demandas da maioria convergem para a maximização de sua utilidade (BARCELOS, 2007).

Existem modelos teóricos inseridos no contexto do flypaper effect que explicam o fenômeno da expansão dos gastos públicos ao longo do tempo. Entre as principais concepções, destacam-se os modelos de maximização do orçamento (budgetmaximizing model, também denotado de modelo burocrático) e de ilusão fiscal.

Em um primeiro momento, os estudos em torno do modelo burocrático se reportam aos trabalhos de Niskanen (1971). A definição leva a efeito a assimetria de informações entre a corrente governista e o eleitor médio. Os burocratas, por se encontrarem estabelecidos no poder em mandato definido, não possuem incentivos suficientes para revelar o nível de financiamento da máquina pública aos cidadãos. Assim, a transparência e fidedignidade das informações disponibilizadas se vê prejudicada, posto que os burocratas se utilizam de distorções para manter margem orçamentária mais elevada para executar despesas que melhor convém aos interesses do governo instituído.

Com isso, o eleitor médio desconhece a real restrição orçamentária do governo, principalmente em relação a programas de seu interesse, repercutindo em gastos públicos maiores em áreas que não necessariamente beneficiam a sociedade. Isto é, o administrador burocrata manipula a peça orçamentária, reduz gastos com os programas populares e aloca os recursos da maneira que melhor convém a seus interesses, sejam eles pessoais ou políticos (CORREIA, 2014).

Dessa forma, os administradores do setor público, na condição de maximizadores de orçamento, não têm nenhum incentivo para corrigir as percepções dos eleitores em relação aos impostos cobrados. Pelo contrário, suportariam gastos públicos maiores do que deveriam se estivessem sob ambiente de informação perfeita, o que caracteriza o efeito flypaper, muito embora os eleitores não estejam completamente cientes da ocorrência de repasses intergovernamentais (TURNBULL, 1992). 
Já a teoria da ilusão fiscal foi inicialmente desenvolvida por Puviani (1903). Diz respeito à capacidade dos governos em manipular a própria gestão fiscal, criando “ilusão" de que não possui recursos quando de fato possui, e que está gastando quando na verdade não está. Essa postura permite que custos sejam ocultados, e benefícios de programas desejados pela cúpula governista sejam majorados. 0 resultado da manipulação fiscal distorce as percepções do eleitor médio, prejudicado em um ambiente de informação imperfeita que lhe impede de demandar bens e serviços públicos que seriam, de fato, de seu interesse (ARAUJO; SIQUEIRA, 2016).

A ilusão fiscal muitas vezes se confunde com o modelo burocrático. Isso porque os agentes políticos aproveitam as falhas de percepção do eleitorado sobre os custos dos bens públicos para maximizar o orçamento. Como os repasses efetivados aos entes subnacionais reduzem o custo médio dos bens públicos, o fato pode causar aos eleitores a falsa impressão de que os custos médios e marginais são equivalentes (RIOS; COSTA, 2005).

Buchanan (1967) registra que o comportamento dos indivíduos frente à ilusão fiscal não é necessariamente irracional. Na verdade, a presença de ilusão fiscal não causa interferências nas decisões dos particulares, cujos alicerces são a coerência e consistência, seja em decorrência do ambiente de informação imperfeita ou não. Mas, o contribuinte não tem condições de atingir discernimento suficiente sobre a existência de ilusão fiscal, a ponto de se relacionar com os burocratas e exigir que suas demandas sejam satisfeitas.

Nessa ausência de compreensão, os governos possuem total controle das informações, divulgando aquelas que Ihe são favoráveis. Assim, as transferências intergovernamentais criam a ilusão de que os bens e serviços providos pelos governos locais são financiados por não residentes, facilitando a expansão do gasto público. Economistas elucidam, ao menos, três fontes de ilusão fiscal: 1) a complexidade do sistema tributário; 2) a visibilidade dos tributos; e 3) o impacto gerado pelos repasses intergovernamentais no financiamento dos gastos públicos, sendo que este último representa a própria aplicabilidade do efeito flypaper (ARAUJO; SIQUEIRA, 2016).

O efeito flypaper sob a ótica da ilusão fiscal reproduz uma visão míope do eleitor mediano sobre as decisões alocativas e distributivas do governo - vale lembrar que, sob a teoria do eleitor médio, o aumento na arrecadação do governo local advindo do sistema de transferências seria acompanhado de aumento proporcional nas despesas 
públicas do ente federativo, o que, de certa forma, conflita com os gastos crescentes observados no efeito flypaper. Logo, os burocratas ofertam cestas de bens e serviços públicos que, apesar de serem mesmo demandados pelo eleitorado, não coincidem com as exigências e desejos de um ambiente sem assimetria de informação (NOJOSA; LINHARES, 2015).

Existem casos que é possível conciliar o efeito flypaper com a hipótese do eleitor médio. Por exemplo, quando os tributos não são cobrados eficientemente pelos governos locais. Daí, quando o montante oriundo de repasses intergovernamentais não é suficiente ante a baixa arrecadação de receita, os governos seriam forçados a suprir a demanda reprimida da sociedade, de maneira a elevar seu bem-estar. Isso viabiliza e estimula ainda mais para que os gastos públicos sejam proporcionalmente superiores às receitas de transferências, só que no contexto de maximização de utilidade do contribuinte (ARVATE; BIDERMAN, 2004).

Ressalta-se, contudo, que informação imperfeita não pode ser confundida com ilusão fiscal. Trata-se de condição necessária, mas não suficiente para a hipótese em referência, isso porque a ilusão fiscal, ao ensejar os diversos vieses das decisões orçamentárias, é recorrente e sistemática, ao contrário da aleatoriedade e pontualidade atribuíveis à informação imperfeita (OATES, 1988). 


\section{PROCEDIMENTOS METODOLÓGICOS}

Com a finalidade de obter evidências do efeito flypaper nos municípios brasileiros, o presente estudo teve por base a abordagem estática de modelo de dados em painel. Entre as justificativas para adoção desse método, tem-se a própria forma organização dos dados, o contínuo período em exame e a grande quantidade de elementos a serem observados - foram coletados dados referentes a 5.606 municípios entre 2005 e 2015, o que corresponde ao total de 61.666 observações.

Assim, utilizou-se estratégia similar à adotada em vários trabalhos já feitos sobre a matéria, a exemplo das discussões levantadas por Correia (2014), Rios e Costa (2005), Cossio e Carvalho (2001), entre outros.

O modelo geral de análise de dados em painel pode ser descrito na forma de uma equação de regressão linear múltipla:

$$
Y_{i t}=\beta_{0 i t}+\beta_{1 i t} X_{1 i t}+\cdots+\beta_{k i t} X_{k i t}+\varepsilon_{i t}
$$

Sendo que $i$ é o número de indivíduos da amostra, $t$ é o período de tempo, $\beta_{0}$ é o parâmetro de intercepto, $\beta_{k}$ é o coeficiente angular referente a $k$-ésima variável independente/explicativa $X$ e $\varepsilon$ é o termo de erro estocástico.

Todavia, deve-se estabelecer premissas para que a equação (1) se torne aplicável. Para a abordagem de dados em painel, a literatura enfatiza os modelos regressivos de efeitos fixos e aleatórios como aqueles de maior adequabilidade para explicar o relacionamento entre as variáveis.

$\mathrm{Na}$ formulação com efeitos fixos, supõe-se que cada elemento da amostra é heterogêneo, fato esse que exerce influência ao interpretar as variáveis independentes. Esse modelo visa controlar o efeito que as invariantes no tempo causam nas variáveis explicativas, sendo que o termo independente representa a heterogeneidade, distinto para cada indivíduo e constante ao longo do tempo. Dessa forma, o intercepto é um parâmetro fixo (variável não aleatória) que retrata as divergências de cada um dos elementos que compõem a amostra. Tal modelo é assim representado:

$$
Y_{i t}=\alpha_{i}+\beta_{1 i t} X_{1 i t}+\cdots+\beta_{k i t} X_{k i t}+\varepsilon_{i t}
$$


Sendo que $\alpha_{i}$ representa o intercepto específico a ser estimado para cada indivíduo.

O estimador de efeitos fixos tem por base os desvios das variáveis explicativas em relação aos valores médios, eliminando o efeito da heterogeneidade. Esse processo é obtido por intermédio do método dos Mínimos Quadrados Ordinários (Ordinary Least Squares - OLS).

A formulação com efeitos fixos surge como melhor opção para modelagem de dados em painel quando o intercepto $\alpha_{i}$ possui correlação com variáveis explicativas em qualquer tempo. Portanto, convém utilizar a regressão com efeitos fixos quando as observações são extraídas de toda a população e as inferências são feitas para aqueles elementos da amostra em que há disponibilização de dados (DUARTE; LAMOUNIER; TAKAMATSU, 2007).

Já no modelo com efeitos aleatórios, também se presume que os indivíduos apresentam heterogeneidade, só que o efeito que a diferenciação causa às variáveis explicativas é absorvido pelo componente de erro, e não diretamente pelo intercepto:

$$
Y_{i t}=\alpha_{i}+\beta_{1 i t} X_{1 i t}+\cdots+\beta_{k i t} X_{k i t}+\omega_{i t} ; \text { onde } \omega_{i t}=\eta_{i}+\varepsilon_{i t}
$$

Sendo $\omega_{i t}$ o componente de erro idiossincrático e $\eta_{i} \circ$ efeito aleatório não observado. Hill, Judge e Griffiths (1999) registram quatro propriedades do termo de erro $\omega_{i t}$ :

$$
\begin{gathered}
\mathrm{E}\left(\omega_{i t}\right)=0 \\
\operatorname{Var}\left(\omega_{i t}\right)=\sigma_{\eta}^{2}+\sigma_{\varepsilon}^{2} \\
\operatorname{Cov}\left(\omega_{i t}, \omega_{i s}\right)=\sigma_{\eta}^{2}, \forall t \neq s \\
\operatorname{Cov}\left(\omega_{i t}, \omega_{j t}\right)=0, \forall i \neq j
\end{gathered}
$$

As duas primeiras propriedades retratam a homocedasticidade do erro (média igual a zero e variância constante). Ou seja, a homocedasticidade retrata a predisposição dos dados em ficarem concentrados em torno da reta de regressão, justificada pela apresentação constante do termo de erro e da variável dependente. Diferentemente da heterocedasticidade, em que as variâncias apresentadas não são uniformes. A terceira propriedade aduz que há correlação entre os termos de erro de um mesmo indivíduo em períodos de tempo diferentes, o que se denomina de autocorrelação ou correlação serial. A autocorrelação pode indicar a existência de 
coeficiente $R^{2}$ indevidamente elevado, ou então que os testes de significância realizados não apresentem validade, o que exige cuidados na análise de regressão e correlação. Enfim, a quarta propriedade ilustra que não existe correlação entre erros de indivíduos distintos no mesmo instante de tempo (BRUNI, 2007).

O estimador de efeito aleatório é obtido mediante uso dos Mínimos Quadrados Generalizados - MQG (Generalized Least Squares - GLS), por intermédio da aplicação do método de Gauss-Markov. Isso por causa da propriedade da autocorrelação, indicando não ser conveniente a aplicação do MQO.

Conhecidos os estimadores dos efeitos fixos e aleatórios, a execução do teste de especificação de Hausman permite indicar qual deles é predominante. Trata-se de teste estatístico que permite avaliar quais dos modelos econométricos citados apresentam maior consistência e confiabilidade, para fins de escolha da base de análise.

O teste de Hausman possui distribuição $\chi^{2}$ assintótica, cuja hipótese nula é de que não há distinção significativa entre os estimadores dos modelos fixo e aleatório. Dessa forma, caso o teste indique que a hipótese nula deva ser rejeitada, é preferível adotar o modelo de efeitos fixos ao invés do modelo aleatório (GUJARATI, 2011).

Foram utilizadas técnicas próprias de estatística descritiva como forma de se obter um breve diagnóstico das variáveis. Em seguida, foram feitos testes econométricos preliminares com o objetivo de verificar a adequação dos pressupostos dos modelos de regressão, a exemplo da multicolinearidade, autocorrelação e heterocedasticidade. Enfim, procedeu-se análises de significância estatística do modelo determinado pelo teste de especificação de Hausman, sendo que as principais serão descritas a seguir. Vale lembrar que o nível de significância determinado para esta pesquisa é de $5 \%$.

O teste $\mathrm{F}$ permite aferir se o modelo econométrico como um todo é globalmente significativo. Portanto, a estatística $F$ objetiva verificar se existe relação significativa entre a variável dependente e o conjunto de todas as variáveis explicativas. Também é conhecido como teste de significância global.

As hipóteses aplicáveis ao teste $\mathrm{F}$ são: $H_{0}: \beta_{1}=\beta_{2}=\cdots \beta_{K}=0 ; H_{a}: \beta_{k} \neq$ 0 (qualquer parâmetro diferente de zero). Desta forma, infere-se que, se $H_{0}$ for rejeitada, o teste evidencia que a relação entre a variável dependente e o conjunto de 
variáveis independentes é significativa. Considerando o cenário de rejeição da hipótese nula, o teste t pode ser feito para verificar se cada uma das variáveis independentes individualmente consideradas é estatisticamente significativa. Por isso, a estatística t também é conhecida como teste de significância individual.

Tem-se as seguintes hipóteses para o teste $\mathrm{t}$, para qualquer $\beta_{k}: H_{0}: \beta_{k}=$ $0 ; H_{a}: \beta_{k} \neq 0$. Do mesmo modo que no teste $\mathrm{F}$, se $H_{0}$ for rejeitada, tem-se indício de que a variável explicativa em questão é estatisticamente significativa.

O coeficiente $R^{2}$ visa medir a qualidade de ajustamento da equação de regressão múltipla estimada. Pode ser interpretado como a proporção da variável dependente que pode ser explicada pela equação de regressão como um todo (SWEENEY; WILLIAMS; ANDERSON, 2013).

A metodologia utilizada nesta pesquisa viabiliza analisar os níveis de colinearidade das variáveis explicativas, bem assim o aumento do número de informações a partir da combinação de dados e a investigação do conjunto de indivíduos heterogêneos. Cabe registrar que foi utilizado como ferramenta de suporte e referência no processo de análise dos dados e da escolha do modelo econométrico o software estatístico Stata - Data Analysis and Statistical Software, versão 13 (CORREIA, 2014).

Para atingir os objetivos estabelecidos neste trabalho, foram definidas as variáveis subsequentes para confirmar o efeito flypaper: despesa corrente, população, repasses intergovernamentais recebidos, Produto Interno Bruto (PIB) e receita tributária. Ao trazê-las para o formato da equação (1), tem-se que:

$$
\text { lnDespesa }_{i t}=\alpha_{i}+\beta_{1} \text { lnPop }_{i t}+\beta_{2} \text { lnRepasses }_{i t}+\beta_{3} \text { InPIB }_{i t}+\beta_{4} \text { lnReceita }_{i t}+\varepsilon_{i t}
$$

Sendo InDespesa $_{i t}$ o logaritmo neperiano do total das despesas correntes empenhadas do $i$-ésimo município no ano $t$; $\ln P o p_{i t}$ o logaritmo neperiano da população residente no i-ésimo município no ano t; InRepasses $_{i t}$ o logaritmo neperiano das transferências correntes recebidas pelo i-ésimo município no ano $\mathrm{t}$; $\ln P I B_{i t}$ o logaritmo neperiano do Produto Interno Bruto do i-ésimo município no ano t; $\operatorname{lnReceita}_{i t} \mathrm{O}$ logaritmo neperiano da receita tributária arrecadada pelo $i$-ésimo município no ano $t$; e $\varepsilon_{i t}$ o componente de erro. 
Registra-se que é prática comum o uso do coeficiente de logaritmo natural junto às variáveis explicativas, posto que sua utilização traz estímulos à linearização e possibilita realizar estimativas com valores nominais e com elasticidades.

As variáveis de execução orçamentária foram extraídas de aplicativos e sistemas web de banco de dados da Secretaria do Tesouro Nacional (STN), denominado Finanças do Brasil - Dados Contábeis dos Municípios (Finbra). Tais dados contemplam os registros contábeis patrimoniais e orçamentários relativos aos balanços consolidados municipais, cujas informações são fornecidas pelos próprios municípios à STN. Já os dados de população residente e dos PIBs municipais foram consultados junto à página eletrônica do Instituto Brasileiro de Geografia e Estatística (IBGE).

A receita tributária segue as classificações orçamentárias e contábeis definidas pela STN em cada exercício financeiro, sendo a arrecadação basicamente composta por impostos, taxas e contribuições de melhoria.

Os repasses intergovernamentais tratam de valores recebidos pelos municípios a título de transferências correntes, a exemplo das cotas-parte dos Fundos de Participação dos Municípios (FPM) e de impostos como o Imposto sobre Circulação de Mercadorias e Serviços (ICMS) e Imposto sobre a Propriedade de Veículos Automotores (IPVA).

Para a variável despesa corrente, foram consideradas as despesas empenhadas, por espelharem adequadamente o efeito dos restos a pagar não processados inscritos ao final de cada exercício financeiro. Integram o grupo corrente as despesas com pessoal, juros e encargos da dívida e outras despesas correntes.

Foram enfrentadas limitações no levantamento dos dados, tendo em conta que a base de dados do Finbra depende de informações repassadas pelos municípios à STN, não abrangendo a totalidade destes. Além disso, o IBGE não disponibilizou dados da população residente para todos os períodos. Nessa falta, utilizou-se os dados divulgados pelo próprio Finbra para complementação. Apesar disso, as limitações não se mostraram relevantes a ponto de prejudicar a análise por falta de dados, dada a representatividade da amostra coletada.

O Quadro 1 traz um resumo das variáveis explicativas e os respectivos efeitos esperados sobre os gastos públicos. 
Quadro 1 - Descrição das variáveis explicativas.

\begin{tabular}{|l|l|}
\hline \multicolumn{1}{|c|}{ Variável } & \multicolumn{1}{c|}{ Expectativas } \\
\hline População & Positivo \\
\hline Transferências & Positivo \\
\hline PIB & Negativo \\
\hline Receita & Positivo \\
\hline
\end{tabular}

Fonte: Elaboração própria.

Espera-se que variações positivas na receita tributária municipal arrecadada promovam maior oferta de bens e serviços públicos à sociedade, repercutindo no aumento nos gastos públicos. Essa expectativa é compatível, inclusive, com o princípio do equilíbrio orçamentário, em que as receitas igualam as despesas.

No mesmo sentido, é esperado que a receita auferida pelos munícipios decorrente de repasses intergovernamentais também eleve o montante dos dispêndios. Todavia, o atual panorama da administração pública brasileira (situação delicada das finanças públicas municipais, com redução da arrecadação e elevação do contingenciamento de despesas) permite supor que o crescimento dos gastos não seja demasiadamente elástico ao observado pela variável transferências, o que não confirmaria a hipótese do efeito flypaper.

Há expectativa de que também haja aumento na demanda e na provisão de bens públicos (ex.: saúde, educação, segurança, entre outros), em virtude do crescimento da população residente. Logo, as variações positivas das populações tendem a gerar efeitos crescentes nos dispêndios públicos.

Ressalta-se que a variação das despesas correntes em função dos aumentos na produção interna não é necessariamente positiva. Sob o ponto de vista macroeconômico, o crescente nível de produção municipal tende a elevar a renda e a formar poupança pública, estimulando as exportações e desencorajando as importações. Detidos de maior capacidade econômica, os governos detêm maiores condições financeiras de realizar investimentos de longo prazo nas mais variadas áreas de atuação pública, em detrimento à execução dos gastos correntes. Dessa forma, estabelece-se a hipótese de que a relação entre despesa corrente e PIB é negativa. 


\section{ANÁLISE DOS RESULTADOS}

A Tabela 2 sintetiza os cálculos dos principais índices de estatística descritiva.

Tabela 2 - Estatística descritiva dos municípios brasileiros (valores monetários em reais).

\begin{tabular}{l|ccccc}
\hline Estatística & Despesa & Pop. & Repasses & PIB & Receita \\
\hline Soma & $3,25 \mathrm{e}+12$ & $2,06 \mathrm{e}+09$ & $2,50 \mathrm{e}+12$ & $3,18 \mathrm{e}+10$ & $8,19 \mathrm{e}+11$ \\
Média & $5.27 \mathrm{e}+07$ & $33.385,5$ & $4,06 \mathrm{e}+07$ & $516.164,7$ & $1,33 \mathrm{e}+07$ \\
Mediana & $1,33 \mathrm{e}+07$ & $10.516,5$ & $1,45 \mathrm{e}+07$ & $56.659,96$ & $642.928,6$ \\
Variância & $2,34 \mathrm{e}+17$ & $4,12 \mathrm{e}+10$ & $4,42 \mathrm{e}+16$ & $3,88 \mathrm{e}+13$ & $6,45 \mathrm{e}+16$ \\
Desvio & $4,84 \mathrm{e}+08$ & $202.984,6$ & $2,10 \mathrm{e}+08$ & 6.228 .062 & $2,54 \mathrm{e}+08$ \\
Padrão & & & & & \\
CV & 9,180154 & 6,080025 & 5,174299 & 12,06604 & 19,12908 \\
Assimetria & 48,3755 & 38,00453 & 39,05494 & 55,90809 & 53,9817 \\
Curtose & 2984,107 & 1893,445 & 2170,959 & 3967,572 & 3489,868 \\
\hline
\end{tabular}

Fonte: Elaboração própria, a partir dos dados obtidos na pesquisa.

Infere-se dos dados que a média das despesas correntes municipais é superior à média das demais variáveis, em especial os repasses intergovernamentais correntes recebidos (superior em $29,76 \%$ em relação a esta última), o que, a princípio, reforçaria a hipótese de que a elasticidade gasto/repasse seja superior à unidade.

A soma das receitas tributárias no período é de aproximadamente $R \$ 818,6$ bilhões, e das despesas correntes, $R \$ 3,2$ trilhões. Ressalta-se a baixa representatividade da arrecadação, à medida que compõe apenas 25,2\% do total dos referidos gastos. Nesse sentido, é interessante notar que a média do ritmo de arrecadação de tributos ( $R$ \$ 13,3 milhões) também não consegue acompanhar a média de execução da variável dependente ( $R$ \$ 52,7 milhões).

Aferiu-se uma base média de receita tributária de $\mathrm{R} \$ 13,3$ milhões que, relacionado com a média populacional de $\mathrm{R} \$ 33,4$ mil indivíduos, alcança um montante médio superior a $R \$ 397$ reais de impostos pagos por cada contribuinte. Essa média populacional também indica uma proporção razoavelmente capaz de estimular a geração de renda (faixa média de $\mathrm{R} \$ 516$ mil). 
Os índices de assimetria indicam que a distribuição das variáveis é positiva (assimétrica à direita), dado que as médias são superiores às medianas. Por outro lado, os Coeficientes de Variação (CV), que indicam a relação desvio padrão/média, se mostraram elevados, o que reduz a precisão na análise comparativa das variáveis.

Ao verificar a correlação das variáveis despesa corrente e repasses mediante o coeficiente de Pearson, chegou-se ao índice de 0,96, o que traduz uma forte correlação entre elas. O gráfico a seguir elucida essa correlação.

Figura 1 - Correlação entre despesas correntes e transferências correntes.

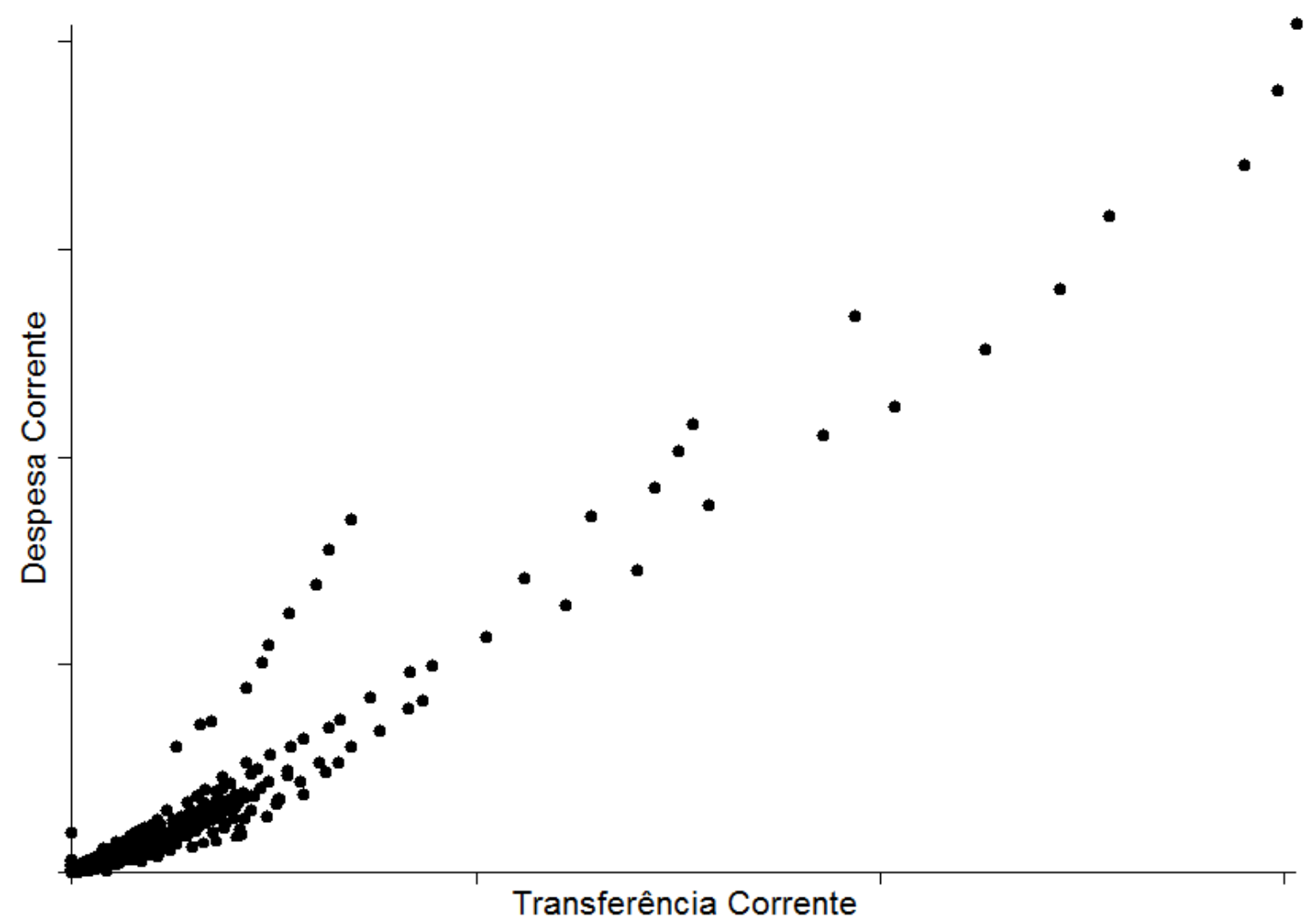

Fonte: Elaboração própria, a partir dos dados obtidos na pesquisa.

Vale lembrar que esta alta correlação não significa que as alterações ocorridas nas transferências intergovernamentais provocam necessariamente variações em ritmo superior nas despesas. Além disso, o conjunto de variáveis como um todo apresentou elevado desvio padrão, o que ainda deixa em aberto a possibilidade de a relação de causa e efeito entre gastos e repasses condizer com o efeito flypaper. 
Em sequência, serão expostos os resultados dos testes preliminares de regressão linear múltipla, com o intuito de confirmar as expectativas em torno das variáveis explicativas e os pressupostos dos modelos de regressão.

Tabela 3 - Resultados dos testes de regressão linear múltipla ( $\alpha=5 \%)$.

\begin{tabular}{|c|c|c|c|c|c|c|c|c|}
\hline \multicolumn{5}{|c|}{ OLS Simples } & \multicolumn{4}{|c|}{ OLS Robusto } \\
\hline Var. & Coef. & Erro & $\mathbf{t}$ & p & Coef. & $\begin{array}{l}\text { Erro } \\
\text { robusto }\end{array}$ & $\mathbf{t}$ & $\mathbf{p}$ \\
\hline Pop. & 0,2213947 & 0,0030989 & 71,44 & 0,00 & 0,2213947 & 0,025574 & 8,66 & 0,00 \\
\hline Repasses & 0,7872038 & 0,001927 & 408,52 & 0,00 & 0,7872038 & 0,0162896 & 48,33 & 0,00 \\
\hline PIB & $-0,0125986$ & 0,000487 & $-25,87$ & 0,00 & $-0,0125986$ & 0,0012414 & $-10,15$ & 0,00 \\
\hline Receita & 0,0939044 & 0,0022155 & 42,39 & 0,00 & 0,0939044 & 0,0119281 & 7,87 & 0,00 \\
\hline Prob. F & & & & & & & & 0,00 \\
\hline $\mathrm{R}^{2}$ & & & & & & & & 0,9802 \\
\hline
\end{tabular}

Fonte: Elaboração própria, a partir dos dados obtidos na pesquisa.

A princípio, os testes de regressão OLS simples e robusto confirmam os efeitos esperados. Com exceção do PIB, os demais parâmetros estimulam o crescimento dos gastos públicos. Considerando que a probabilidade $F$ e $\circ \mathrm{p}$ valor são nulos, e considerando 61.665 graus de liberdade para um $\alpha$ bicaudal $=0,05$, o t calculado para cada variável é superior ao t crítico de 1,96, o que possibilita rejeitar $H_{0}$ e aceitar $H_{a}\left(\beta_{K} \neq 0\right)$. Logo, a estatística t dos testes preliminares revela que cada uma das variáveis é individualmente significativa para explicar o comportamento da despesa corrente no período em análise.

O $R^{2}$ aponta que as variáveis independentes escolhidas explicam 98,02\% da variação nos gastos, estando bem próximo de um ajustamento perfeito. Isso significa que as variáveis explicativas detêm condições de explicar as oscilações na despesa corrente. No entanto, o alto valor do coeficiente de determinação, conciliado com índices elevados de estatística t, traz indícios de que os modelos regressivos possuem multicolinearidade. Apesar disso, o fenômeno tende a não prejudicar a análise, haja vista que os coeficientes de cada variável confirmam as expectativas e os testes t não apresentaram falhas.

O próximo passo resume-se à verificação da existência de autocorrelação e heterocedasticidade. Uma possível presença de tais propriedades pode vir prejudicar 
a confiabilidade das análises, o que demandaria testes complementares para correção dos efeitos. Para a autocorrelação, aplicou-se o teste de Wooldridge para dados em painel, sendo que $H_{0}$ pressupõe-se a ausência de correlação serial, e $H_{a}$, sua constatação. A tabela a seguir ilustra o resultado do referido teste.

Tabela 4 - Resultado do teste de Wooldridge de autocorrelação para dados em painel $(\alpha=5 \%)$.

\begin{tabular}{c|c}
\hline Estatística & Coeficiente \\
\hline $\mathrm{F}(1,5605)$ & 1,609 \\
Probabilidade $\mathrm{F}$ & 0,2046 \\
\hline
\end{tabular}

Fonte: Elaboração própria, a partir dos dados obtidos na pesquisa.

Sendo a probabilidade $\mathrm{F}$ de 0,2046 superior ao nível de significância $\alpha=0,05$, aceita-se $H_{0}$ (não há correlação serial), o que dispensa correções adicionais ao modelo nesse sentido. No tocante à heterocedasticidade, optou-se pela realização dos testes de White e de Breusch-Pagan para sua constatação. Para tanto, discutese as seguintes hipóteses: $H_{0}$ : homocedasticidade; e $H_{a}$ : heterocedasticidade. Os resultados encontram-se expostos na Tabela 5.

Tabela 5 - Resultados dos testes de heterocedasticidade ( $\alpha=5 \%$ ).

\begin{tabular}{l|ll}
\hline Estatística & Teste de White & Teste de Breusch-Pagan \\
\hline$\chi^{2}$ & 24500,19 & 91845,89 \\
Probabilidade & 0,00 & 0,00 \\
\hline
\end{tabular}

Fonte: Elaboração própria, a partir dos dados obtidos na pesquisa.

Os testes indicaram a presença de heterocedasticidade do modelo de hipótese, posto que as probabilidades são nulas e menores que o nível de significância, permitindo rejeitar $H_{0}$ e aceitar $H_{a}$. Em posse deste resultado, mostrou-se conveniente adotar como estratégia a realização do teste de especificação de Hausman para aferir se o modelo de efeito fixo ou o aleatório é o mais indicado e, em fase posterior, proceder aos testes de correção de heterocedasticidade específicos à modelagem definida. Assim, testou-se: $H_{0}$ : indicação do modelo de efeitos aleatórios; e $H_{a}$ : indicação do modelo de efeitos fixos. Os apontamentos a seguir resumem os 
resultados do teste de Hausman, já com os coeficientes estimados por efeitos fixos e aleatórios.

Tabela 6 - Resultado do teste de Hausman, com as estimativas para os modelos de efeitos fixos e aleatórios ( $\alpha=5 \%)$.

\begin{tabular}{|c|c|c|c|c|c|c|c|c|}
\hline \multicolumn{5}{|c|}{ Efeitos Fixos } & \multicolumn{4}{|c|}{ Efeitos Aleatórios } \\
\hline Var. & Coef. & Erro & $\mathbf{t}$ & p & Coef. & Erro & $z$ & p \\
\hline Pop. & 0,776535 & 0,0055289 & 140,45 & 0,00 & 0,2775898 & 0,003515 & 78.97 & 0,00 \\
\hline Repasses & 0,4056866 & 0,0038033 & 106,67 & 0,00 & 0,7564791 & 0,0021658 & 349.29 & 0,00 \\
\hline PIB & $-0,0179846$ & 0,0004464 & -40.29 & 0,00 & $-0,0134848$ & 0,0004772 & -28.26 & 0,00 \\
\hline Receita & 0,2166151 & 0,0036929 & 58,66 & 0,00 & 0,0946654 & 0,0024882 & 38.05 & 0,00 \\
\hline $\mathrm{R}^{2}$ within & & & & 0,9791 & $\mathrm{R}^{2}$ within & & & 0,9752 \\
\hline $\mathrm{R}^{2}$ between & & & & 0,9492 & $\mathrm{R}^{2}$ between & & & 0,9899 \\
\hline $\mathrm{R}^{2}$ overall & & & & 0,9633 & $\mathrm{R}^{2}$ overall & & & 0,9801 \\
\hline $\mathrm{F}$ & & & & 4,33 & Wald $\chi^{2}$ & & & $2,83 e+06$ \\
\hline Prob. F & & & & 0,00 & Prob. $\chi^{2}$ & & & 0,00 \\
\hline \multicolumn{9}{|c|}{ Teste de Especificação de Hausman } \\
\hline$\chi^{2}$ & & & & & & & & 21647,03 \\
\hline Probabilidad & & & & & & & & 0,00 \\
\hline
\end{tabular}

Fonte: Elaboração própria, a partir dos dados obtidos na pesquisa.

O teste de Hausman permitiu concluir que o modelo de maior robustez para a análise de dados em painel nesta pesquisa é a regressão por efeitos fixos, visto que o valor $\chi^{2}$ é altamente significativo para uma probabilidade nula e inferior ao nível de significância definido, a qual permite rejeitar $H_{0}$ e aceitar $H_{a}$.

Com a escolha do modelo de efeitos fixos, e levando a efeito a heterocedasticidade demonstrada na Tabela 5, optou-se por realizar o teste de Wald modificado para verificação de heterocedasticidade grupal, específico para a abordagem de efeitos fixos, com as seguintes hipóteses: $H_{0}$ : homocedasticidade; e $H_{a}$ : heterocedasticidade. A aceitação de $H_{0}$ indica que o modelo de efeitos fixos detém robustez suficiente para analisar a ocorrência do efeito flypaper nos municípios brasileiros. A Tabela 7 traz os resultados do teste de Wald. 
Tabela 7 - Resultado do teste de Wald de heterocedasticidade grupal para o modelo de efeitos fixos $(\alpha=5 \%)$.

\begin{tabular}{c|c}
\hline Estatística & Coeficiente \\
\hline$\chi^{2}$ & $5,8 \mathrm{e}+09$ \\
Probabilidade & 0,00 \\
\hline
\end{tabular}

Fonte: Elaboração própria, a partir dos dados obtidos na pesquisa.

Novamente, observou-se no teste de Wald uma estatística $\chi^{2}$ significativa com probabilidade nula, a qual conclui-se pela rejeição de $H_{0}$ e aceitação de $H_{a}$, persistindo a heterocedasticidade. Diante de tal cenário, optou-se por testar a regressão por efeitos fixos com erros-padrão robustos clusterizados, forçando o relaxamento da hipótese de heterocedasticidade. Os resultados encontram-se expostos na Tabela 8.

Tabela 8 - Resultado dos estimadores para o modelo de efeito fixo, com correção robusta $(\alpha=5 \%)$.

\begin{tabular}{lcccc}
\hline \multicolumn{5}{c}{ Efeitos Fixos com Erros-Padrão Robustos Clusterizados } \\
\hline \multicolumn{1}{c}{ Var. } & Coef. & Erro robusto & $\mathbf{t}$ & \multicolumn{1}{c}{$\mathbf{p}$} \\
\hline Pop. & 0,776535 & 0,0932294 & 8,33 & 0,00 \\
Repasses & 0,4056866 & 0,051884 & 7,82 & 0,00 \\
PIB & $-0,0179846$ & 0,0020845 & $-8,63$ & 0,00 \\
Receita & 0,2166151 & 0,027068 & 8,00 & 0,00 \\
\hline$R^{2}$ within & & & 0,9791 \\
$R^{2}$ between & & & & 0,9492 \\
$R^{2}$ overall & & & 0,9633 \\
Prob. F & & & 0,00 \\
\hline
\end{tabular}

Fonte: Elaboração própria, a partir dos dados obtidos na pesquisa.

De acordo com as informações da Tabela 8, obtém-se as mesmas conclusões em relação aos testes preliminares de regressão OLS simples e robusto, o que justifica a boa escolha das variáveis explicativas para o método proposto. Tendo em conta os altos valores dos coeficientes de determinação, e que a estatística t de cada variável se encontra bem acima do parâmetro crítico de 1,96 (graus de liberdade $=61.665$ e $\alpha$ bicaudal $=0,05)$, com probabilidade $\mathrm{F}$ e $\mathrm{p}$ valor nulos e inferiores ao nível de 
significância, conclui-se pela rejeição de $H_{0}$ e aceitação de $H_{a}$, dando evidências de que as variáveis definidas são estatisticamente significativas, tanto em nível individual quanto global.

Os resultados da abordagem de efeitos fixos permitiram confirmar todas expectativas traçadas em torno das variáveis independentes. Em relação à população, constatou-se que os gastos correntes acompanham o crescimento do contingente populacional em proporções semelhantes. Os resultados indicam que, para cada 1\% de aumento na população municipal, a despesa cresce $0,77 \%$, coeteris paribus.

Análise semelhante pode ser feita em relação à arrecadação tributária: para cada $R \$ 1,00$ auferido, a despesa corrente aumenta $R \$ 0,21$. Considerando que a receita tributária média é inferior ao gasto corrente médio (vide Tabela 2), o que exigirá uma postura de austeridade fiscal dos municípios no longo prazo, e sabendo que a despesa corrente tende a crescer em ritmo inferior à arrecadação, o fato pode indicar uma propensão de que, no futuro, ocorra o fenômeno da capitalização orçamentária, em que o descompasso entre receitas e despesas correntes venha suprir possível insuficiência na arrecadação de receitas de capital, o que pode vir a ocasionar a realização de investimentos públicos com recursos correntes, o que é benéfico à sociedade.

De outro modo, para cada $1 \%$ no aumento na produção, haveria queda de 0,01\% nos gastos públicos. Isso exprime a tendência de que aumentos do PIB viabilizem investimentos em, por exemplo, obras e infraestrutura, do que em despesas correntes. Apesar de comprovar as expectativas, o efeito negativo é ínfimo, o que pode ser atribuído ao atual e preocupante cenário das finanças públicas municipais, residindo na dificuldade de os entes subnacionais melhorarem os respectivos resultados primários, principalmente no tocante à redução da pressão exercida pelas despesas primárias relativas aos gastos com pessoal.

Finalmente, em relação aos repasses intergovernamentais, para uma variação de $1 \%$ no aumento nos valores arrecadados pelos municípios a título de transferências correntes, a despesa corrente eleva em aproximadamente 0,4\% para um nível de significância de 5\%, coeteris paribus. Ou seja, os testes econométricos permitiram verificar que a realidade econômica e fiscal dos municípios brasileiros no período em exame não se alinha com os preceitos do efeito flypaper, visto que a elasticidade gasto/repasse não é superior à unidade. Vale lembrar que esta medida de 
sensibilidade também não foi detectada em nenhum dos testes realizados neste trabalho, como se pode depreender dos resultados elencados pelas Tabelas 3,6 e 8 . 


\section{CONSIDERAÇÕES FINAIS}

A presente pesquisa teve por finalidade verificar a ocorrência do efeito flypaper nos municípios brasileiros, posto que o fenômeno poderia explicar a grave situação econômica e fiscal de muitos dos entes federativos em questão. Portanto, objetivouse averiguar qual seria a relação entre os repasses recebidos pelos municípios e os seus respectivos gastos públicos. Para tanto, foram definidas as principais variáveis que traduzem a execução orçamentária e financeira dos municípios (receita tributária, despesa corrente, transferências correntes, população municipal e PIB) e coletados os dados referentes aos exercícios de 2005 a 2015.

Os resultados da aplicação da abordagem de modelo de dados em painel com efeitos fixos revelaram que o flypaper effect não é aplicável no período avaliado. Uma série de fatores podem explicar tais resultados.

Por exemplo, a arrecadação de receitas tributárias pode ter sido insuficiente, pois existem municípios que não exercem, de forma plena, a atribuição legal de instituir, prever e arrecadar tributos de sua competência, dependendo da transferência de recursos financeiros de entes superiores para atender as demandas coletivas. Portanto, ao dependerem basicamente de ingressos oriundos de transferências, há tendência natural em retrair os gastos, principalmente em um cenário de baixa arrecadação de tributos. É interessante notar como o efeito flypaper também se relaciona com a questão da eficiência na formação da base tributária municipal.

Além disso, é relevante dizer que, ao tempo em que existem municípios que não cumprem esta competência legal em específico, uma análise sob a ótica da despesa permite inferir que a falta de maiores estímulos à execução de gastos correntes em decorrência dos repasses é um indicativo de que os gestores têm receio, por exemplo, à normatização estabelecida pela Lei Complementar no 101/2000 (Lei de Responsabilidade Fiscal), muito em conta da possibilidade de punições em virtude de seu descumprimento. Cita-se, a título de ilustração, os limites definidos por esta norma para o montante de despesas com pessoal de cada ente federativo (principal rubrica da categoria de gasto corrente). Logo, as despesas até podem crescer com o advento das transferências, mas não se espera que isso ocorra em ritmo superior aos ingressos em referência. 
Pelo exposto, conclui-se que os objetivos estabelecidos para este trabalho foram atingidos, quais sejam, a caracterização e confirmação da aplicabilidade (ou não) do efeito flypaper nos municípios brasileiros. Para futuras investigações sobre o tema, sugere-se inserir variáveis adicionais referentes à execução orçamentária e financeira dos municípios, a exemplo de receitas e despesas de capital, bem como a ampliação temporal do escopo para fins de análise de dados em painel, o que daria abrangência ainda maior para a apuração.

\section{REFERÊNCIAS}

ARAUJO, Jevuks Matheus; SIQUEIRA, Rozane Bezerra. Demanda por gastos públicos locais: evidências dos efeitos de ilusão fiscal no Brasil. Estudos Econômicos, São Paulo, v. 46, n. 1, p. 189-219, jan-mar. 2016.

ARVATE, Paulo Roberto; BIDERMAN, Ciro. Economia do setor público no Brasil. Rio de Janeiro: Campus Elsevier, 2004.

BALEEIRO, Aliomar. Uma introdução à ciência das finanças. 15. ed. Rio de Janeiro: Forense, 1997.

BARCELOS, Carlos Leonardo Klein. Determinantes da despesa pública local: um estudo empírico dos municípios brasileiros à luz do teorema do eleitor mediano. 2007. 111 f. Dissertação (mestrado em Ciências Contábeis) - Universidade de Brasília, Brasília, 2007.

BRUNI, Adriano Leal. Estatística aplicada à gestão empresarial. 1. ed. São Paulo: Atlas, 2007.

BURKHEAD, Jesse. Orçamento Público. Rio de Janeiro: Fundação Getúlio Vargas, 1971.

CORREIA, José Geraldo Araújo. Analisando o comportamento dos gastos públicos nos municípios cearenses: uma análise do efeito flypaper. 2014. $29 \mathrm{f}$. Dissertação (mestrado em Economia) - Universidade Federal do Ceará, Fortaleza, 2014. 
COSER, Ivo. O conceito de federalismo e a ideia de interesse no Brasil do século XIX. Revista de Ciências Sociais, Rio de Janeiro, v. 51, n. 4, p. 941-981, 2008.

COSSIO, Fernando Andrés Blanco; CARVALHO, Leonardo Mello de. Os efeitos expansivos das transferências intergovernamentais e transbordamentos espaciais de despesas públicas: evidências para os municípios brasileiros 1996. Pesquisa e Planejamento Econômico, Rio de Janeiro, v. 31, n. 1, p. 75-124, abr. 2001.

COURANT, Paul N.; GRAMLICH, Edward M.; RUBINFELD, Daniel L. The stimulative effects of intergovernmental grants: or why money sticks where it hits. In: Fiscal Federalism and Grants-In-Aid, p. 5-21, Washington DC: The Urban Institute, 1979.

DUARTE, Patrícia C.; LAMOUNIER, Wagner M.; TAKAMATSU, Renata T. Modelos econométricos para dados em painel: aspectos teóricos e exemplos de aplicação à pesquisa em contabilidade e finanças. In: Congresso USP de Controladoria e Contabilidade, v. 7. Congresso USP de Iniciação Científica em Contabilidade, 4. 2007, São Paulo. Anais... São Paulo, 2007. p. 1-15.

GORDON, Roger. An optimal tax approach to fiscal federalism. Quarterly Journal Economics, v. 98, n. 4, p. 567-586, 1983.

GUEDES, Kelly Pereira; GASPARINI, Carlos Eduardo. Descentralização fiscal e tamanho do governo no Brasil. Economia Aplicada - Brazilian Journal of Applied Economics, São Paulo, v. 11, n. 2, p. 303-323, abr-jun. 2007.

GUJARATI, Damodar N.; PORTER, Dawn C. Econometria básica. Tradução por Denise Duarte, Mônica Rosemberg e Maria Lúcia G. L. Rosa. 5. ed. Porto Alegre: AMGH, 2011.

HILL, R. Carter; JUDGE, George G.; GRIFFITHS, William E. Econometria. São Paulo: Saraiva, 1999.

JUND, Sérgio. Administração, orçamento e contabilidade pública. Rio de Janeiro: Campus Elsevier, 2008. 
LIMA, Edilberto Carlos Pontes. Curso de finanças públicas: uma abordagem contemporânea. São Paulo: Atlas, 2015.

MENDES, Sérgio. Administração financeira e orçamentária: teoria e questões. 4. ed. São Paulo: Método, 2013.

NISKANEN, William A. Bureaucracy and representative government. Chicago: Aldine-Atherton, 1971.

NOJOSA, Glauber Marques; LINHARES, Fabrício Carneiro. Variabilidade do efeito flypaper e força política: uma análise para os municípios brasileiros. In: XVIII Encontro de Economia da Região Sul, 2015, Rio Grande do Sul. Anais... Rio Grande do Sul: Universidade Federal do Rio Grande do Sul, 2015. Disponível em: < http://www.ppge.ufrgs.br/anpecsul2015/artigo/VARIABILIDADE_DO_EFEITO.pdf>. Acesso: 13 jan. 2017.

OATES, Wallace E. Fiscal Federalism. Nova York: Harcourt Brace Jovanovich, 1972.

On the nature and measurement of fiscal illusion: a survey. In: Taxation and Fiscal Federalism: Essays in Honour of Russell Mathews, edited by G. Brennan et al., p. 65-82. Sydney: Australian National University Press, 1988.

PEACOCK, Alan T. WISEMAN, Jack. The growth of public expenditure in the United Kingdom. Princeton University Press, 1970.

PISCITELLI, Tathiane. Direito Financeiro Esquematizado. São Paulo: Método, 2011.

PUVIANI, Amilcare. Teoria della illusione finanziaria. Milan: Remo Sandron, 1903.

RIOS, Maria Emília; COSTA, José da Silva. O efeito flypaper nas transferências para os municípios portugueses. Revista portuguesa de estudos regionais, n. 8, p. 85-108, 2005.

SAKURAI, Sergio Naruhiko. Efeitos assimétricos das transferências governamentais sobre os gastos públicos locais: evidências em painel para os municípios brasileiros. Pesquisa e Planejamento Econômico, v. 43, n. 2, p. 309-332, ago. 2013 
SEVERO FILHO, Francisco Ailson Alves. Análise do flypaper effect e sua variabilidade nos municípios cearenses. 2012. 42 f. Dissertação (mestrado em Economia) - Universidade Federal do Ceará, Fortaleza, 2012.

SILVA, Fernando Rezende da. Finanças públicas. São Paulo: Atlas, 1979.

SWEENEY, Dennis J.; WILLIAMS, Thomas A.; ANDERSON, David R. Estatística aplicada à administração e economia. Tradução por Solange Aparecida Visconti. 3. ed. São Paulo: Cengage Learning, 2013.

TIEBOUT, Charles M. A pure theory of local expenditures. The Journal of Political Economy, v. 64, n. 5, p. 416-424, 1956.

TURNBULL, Geoffrey K. Fiscal illusion, uncertainty, and the flypaper effect. Journal of Public Economics, n. 48, p. 207-223, 1992.

. The overspending and flypaper effects of fiscal illusion: theory and empirical evidence. Journal of Public Economics, n. 44, p. 1-26, 1998.

WYCOFF, Paul Gary. A bureaucratic theory of flypaper effects. Journal of Urban Economics, v. 23, p. 115-129, 1988. 